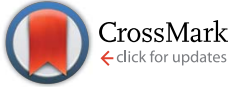

Cite this: RSC Adv., 2015, 5, 68796

Received 24th June 2015 Accepted 5th August 2015

DOI: $10.1039 / \mathrm{c} 5 \mathrm{ra12218j}$

www.rsc.org/advances

\section{Stem cell differentiation on conducting polyaniline}

\author{
P. Humpolíček, ${ }^{\star a b}$ K. A. Radaszkiewicz, ${ }^{C}$ V. Kašpárková, bd J. Stejskal, e M. Trchová,
} Z. Kuceková, ${ }^{\mathrm{b}}$ H. Vičarová, ${ }^{c} \mathrm{~J}$. Pacherník, ${ }^{\text {cf }}$ M. Lehocký ${ }^{\mathrm{b}}$ and A. Minařík ${ }^{\mathrm{bg}}$

Polyaniline is a promising conducting polymer with broad application potential in biomedicine. Its medical use, however, requires both biocompatibility and suitable physico-chemical and surface properties. The microstructure, electrical properties, and surface characteristics of polyaniline salt, polyaniline base, and polyaniline deposited with biologically active poly(2-acrylamido-2-methyl-1-propanesulfonic acid) were revealed using atomic force microscopy, contact angle measurements, and Raman spectroscopy. As conducting polymers can be preferentially applied in tissue engineering of heart and nervous tissues, the cardiomyogenesis in pure cardiomyocytes derived from embryonic stem cells and neurogenesis in neural progenitors isolated from embryonal $13 \mathrm{dpc}$ brain were further investigated. The results show that neither cardiomyogenesis nor neurogenesis were influenced by any of the tested polyaniline films. However, the most favorable cell behaviour was observed on pristine polyaniline base; therefore, polyaniline in pristine forms without any further modification can be applied in a variety of biomedical fields.

\section{Introduction}

It is well known that different polyaniline forms (emeraldine salt and base) and their copolymers or blends exhibit different favourable properties such as electrical conductivity and its persistence at various $\mathrm{pH}$. The unique properties of polyaniline make it possible to apply this polymer in biosensors or materials influencing cell behavior through electrical fields. ${ }^{1}$ An electrical field can, for example, stimulate the regeneration of nervous and muscle tissues, ${ }^{2}$ wound healing in skin, ${ }^{3}$ or bone repair. $^{4}$

More recently, the impact of electrical stimuli on cell differentiation and molecular cell parameters has also been revealed. For example, Hsiao et al. ${ }^{5}$ described the application of composite nanofibers of polyaniline and poly(lactic-co-glycolic acid) as an electrically active scaffold for coordinating the beating of cardiomyocytes. Another exciting use of conducting polymers in the electrical stimulation of cells is to induce the

\footnotetext{
${ }^{a}$ Polymer Centre, Faculty of Technology, Tomas Bata University in Zlin, T.G.M. Sq. 5555, 76001 Zlin, Czech Republic.E-mail: humpolicek@ft.utb.cz

${ }^{b}$ Centre of Polymer Systems, Tomas Bata University in Zlin, 76001 Zlin, Czech Republic

'Institute of Experimental Biology, Faculty of Science, Masaryk University, 62500 Brno, Czech Republic

${ }^{d}$ Department of Fat, Surfactant and Cosmetics Technology, Faculty of Technology, Tomas Bata University in Zlin, Zlin, Czech Republic

${ }^{e}$ Institute of Macromolecular Chemistry, Academy of Sciences of the Czech Republic, 16206 Prague 6, Czech Republic

${ }^{f}$ Institute of Biophysics, Academy of Sciences of the Czech Republic, v.v.i., Královopolská 135, 61265 Brno, Czech Republic

${ }^{g}$ Department of Physics and Materials Engineering, Faculty of Technology, Tomas Bata University in Zlin, T.G.M. Sq. 5555, 76001 Zlin, Czech Republic
}

pre-commitment of fibroblasts into cardiomyocytes, ${ }^{6}$ neurite growth, and the migration of rodent neural stem cells, ${ }^{7}$ as well as the stimulation of myoblast differentiation. ${ }^{8}$ Recently, nanofibers fabricated through the electrospinning of polyaniline blended with poly(L-lactic acid) were reported to show potential for adipose-derived stem cell proliferation. ${ }^{9}$ It is therefore obvious that conducting polymers in general and polyaniline in particular are promising materials for tissue engineering and regenerative medicine. However, information about cell compatibility of polyaniline is still insufficient and only a limited picture of the biological performance of this polymer exists. Although there are a number of in vivo studies which have focused on the implantability and post-implant evaluation of polyaniline copolymers (mainly with biodegradable polymers), there are only a few examples of in vitro studies focusing on the cell compatibility of polyaniline in pristine form. In addition, different cells and methods of polyaniline preparation were used in these studies. For example, the compatibility of thin films prepared from saturated solutions of polyaniline in $\mathrm{N}$-methyl-2-pyrrolidone with $\mathrm{H} 9 \mathrm{c} 2$ cardiac myoblasts was studied by Bidez et al. ${ }^{10}$ In two other works published by Wang et al., ${ }^{11}$ PC-12 pheochromocytoma cells were used. Polyaniline doped with different acids was studied by Wang et $a l .{ }^{11}$ while polyaniline film fabricated via electroless surface polymerization was employed in the study of Liu et al. ${ }^{\mathbf{1 2}}$ Finally, Bayer et al. $^{13}$ used the NIH/3T3 cell line to investigate cytotoxicity and proliferation of cells on a polyaniline template synthesized with poly(2-acrylamido-2-methyl-1-propanesulfonic acid) (PAMPSA).

One of the considerable advantages of polyaniline consists in its ability to easily form thin films on e.g. nanostructure materials, ${ }^{14}$ which can be further modified using various dopants 
with the aim of changing their surface properties. Among such dopant substances, synthetic polyanions have been observed to exhibit interesting biological properties. Namely, PAMPSA was shown to act against blood clotting in a similar way to heparin, either alone ${ }^{15}$ or incorporated in copolymers. ${ }^{16}$ Setoyama et al. ${ }^{17}$ also reported that PAMPSA is capable of inhibiting the activation of serum complement activity. Humpolíček et al. ${ }^{18}$ revealed that PANI-PAMPSA possesses significant impact on blood coagulation and platelet adhesion. As regards conductivity, a value of about $10^{-2} \mathrm{~S} \mathrm{~cm}^{-1}$ was reported for PANI-PAMPSA, ${ }^{19}$ which is within the typical range of conductivities reported for PANI salt and PANI base, being of the orders $10^{\circ}$ and $10^{-11} \mathrm{~S}$ $\mathrm{cm}^{-1}$, respectively. ${ }^{20}$ These PAMPSA properties are promising for the modification of polyanilines suitable for biomedical applications. The electrochemically polymerized PANI-PAMPSA was previously detected to allow for selective stem cells adhesion. $^{21}$

From the above-provided summary it can be seen that none of the published studies used pristine polyaniline prepared by the oxidative polymerization according to Stejskal and Gilbert ${ }^{20}$ in combination with stem cells to reveal complex cell behavior on these films. Hence, a study describing stem cell adhesion and differentiation on pristine polyaniline was conducted and the results were compared to corresponding tests run on polyaniline films modified with PAMPSA.

\section{Experimental}

\subsection{Preparation of polyaniline films}

Tissue culture dishes (TPP; Switzerland) were coated in situ with films of polyaniline salt (PANI-S) prepared via the oxidation of aniline hydrochloride with ammonium peroxydisulfate. Aniline hydrochloride (2.59 g; Lach-ner; Czech Republic) was dissolved in water to a $50 \mathrm{~mL}$ solution; ammonium peroxydisulfate (5.71 g; Sigma-Aldrich; US) was similarly dissolved to a $50 \mathrm{~mL}$ solution. Both solutions were mixed at room temperature and immediately poured into the culture dishes. ${ }^{22}$ After $1 \mathrm{~h}$, the dishes were emptied and the films of green conducting PANI-S deposited on their walls were rinsed with $0.2 \mathrm{M}$ hydrochloric acid, followed by methanol, and left to dry in air. Some films were deprotonated by immersion in $1 \mathrm{M}$ ammonium hydroxide for $12 \mathrm{~h}$ and thus converted to blue, non-conducting films of polyaniline base (PANI-B).

In order to prepare PANI doped with poly(2-acrylamido-2methyl-1-propanesulfonic acid) (PANI-PAMPSA), the reprotonation of PANI-B with a $7.5 \%(\mathrm{v} / \mathrm{v})$ aqueous solution of PAMPSA (typical molecular weight $M=2 \times 10^{6} \mathrm{~g} \mathrm{~mol}^{-1}$; SigmaAldrich; US) was performed by pouring the PAMPSA solution onto the surface of the PANI-B film. The reaction was left to proceed for $24 \mathrm{~h}$, then the residual PAMPSA solution was poured out and the film was rinsed with methanol and left to dry in air.

\subsection{Surface energy}

Contact angle measurements and determination of surface energy were conducted with the aid of the "SEE system" (surface energy evaluation system) (Advex Instruments, Czech Republic). For polyaniline samples, deionized water, ethylene glycol, and diiodomethane (Sigma-Aldrich; US) were used as testing liquids. The droplet volume of the testing liquids was set to $2 \mu \mathrm{L}$ in all experiments. Ten separate readings were averaged to obtain one representative contact angle value. Using these data, the substrate surface free energy was determined by the "acidbase" method.

\subsection{Atomic force microscopy}

For determination of topographic and surface electrical properties, tunneling atomic force microscopy (AFM) was performed using the PeakForce TUNA module on Dimension ICON (Bruker Corporation; US). Measurements were conducted under laboratory conditions (temperature and atmosphere). The PFTUNA probe (Bruker Corporation; US) with a spring constant of $0.4 \mathrm{~N}$ $\mathrm{m}^{-1}$, covered on both sides with a conductive Pt/Ir layer, was used. The scanning rate was $0.3 \mathrm{~Hz}$ and the peak currents were measured with a $200 \mathrm{mV}$ bias voltage applied to all the examined samples. The peak current signal was determined by Point analysis using NanoScope Analysis software v.1.5. The resulting peak current signal was calculated from the point measurements and expressed as the current value detected at more than $90 \%$ of the measuring points. The surface roughness was determined using both the arithmetic average of the absolute values of surface height deviations measured from the mean plane $\left(R_{\mathrm{a}}\right)$ and the image surface area difference, which is the difference between the images of a three-dimensional surface area and a two-dimensional projected surface area. The results were analyzed according to the ASME B46.12 standard.

\subsection{Raman spectroscopy}

Raman spectra of the films deposited on silicon windows were measured with a Renishaw InVia Reflex Raman microspectrometer. The spectra were excited with a HeNe $633 \mathrm{~nm}$ laser. A research-grade Leica DM LM microscope with an objective magnification $50 \times$ was used to focus the laser beam on the sample placed on an $\mathrm{X}-\mathrm{Y}$ motorized sample stage. The scattered light was analyzed by the spectrograph with holographic grating 1800 lines. A Peltier-cooled CCD detector $(576 \times$ 384 pixels) registered the dispersed light. To avoid degradation of the samples by the laser beam, a reduced beam power has always been used.

\subsection{Cardiomyocytes adhesion}

Prior to in vitro testing, the samples were disinfected by $30 \mathrm{~min}$ of exposure to a UV-radiation source operating at a wavelength of $258 \mathrm{~nm}$ emitted from a low-pressure mercury lamp. The adhesion of in vitro prepared cardiomyocytes was assessed using the following procedure. For the preparation of a cardiomyocyte population of high purity, R1 ESC cells ${ }^{23}$ were transfected by an MHC promotor-dependent selection vector defined by Klug et $a .^{24}$ (kind gift of Dr Field, L. J.). Selected clones with successfully transfected selection vector, were screened for the possibility of cardiomyogenesis and cardiomyocyte isolation. Dulbecco's Modified Eagle's Medium 
(referred as "complete DMEM media") containing 15\% fetal calf serum, $100 \mathrm{U} \mathrm{mL}^{-1}$ penicillin, $0.1 \mathrm{mg} \mathrm{mL}^{-1}$ streptomycin, 100 $\mathrm{mM}$ non-essential amino acids (all from Gibco-Invitrogen; US), $0.05 \mathrm{mM} \beta$-mercaptoethanol (Sigma-Aldrich; US) and $1000 \mathrm{U}$ $\mathrm{mL}^{-1}$ of leukemia inhibitory factor (Chemicon; US) was used for the cultivation. Selected clone HG8 was used for preparation of cardiomyocyte. Cardiomyogenesis of HG8 was induced by elimination of leukemia inhibitory factor from cultivation media and by the formation of embryoid bodies (EBs) prepared in suspension culture of ESC cells using agar-coated bacteriological dishes. ${ }^{25,26}$ From day 14 of differentiation, G418 antibiotics were added to the culture media for a period of six days to select pure cardiomyocyte population. Cardiomyocyte identity was proved by detection the presence of myofibrils using mouse monoclonal antibodies against sarcomeric $\alpha$-actinin, (SigmaAldrich), and followed by secondary antibody (anti-mouse conjugated to FITC, Sigma-Aldrich; Fig. 4). In the next step, the culture was treated by $0.1 \%$ collagenase II for 30 minutes at $37^{\circ} \mathrm{C}$. The cell suspension was mixed by intensive pipetting, and cardiomyocyte clusters were purified from dead cell debris by spontaneous sedimentation, washed, re-suspended in media, and seeded into reference tissue culture dishes and onto all tested polyaniline surfaces. Four different conditions for HG8 cell adhesion were tested: (A) adhesion on the polyaniline surfaces without coating; (B) adhesion on the polyaniline surfaces coated with $0.1 \%$ gelatin; and (A) and (B) cultivated either in (C) serum-free medium (without fetal calf serum) or (D) DMEM-F12 media supplemented by insulin-transferrinselenium (Gibco-Invitrogen; US) referred to here as "ITS media". Cell behavior was continuously observed for 14 days after seeding.

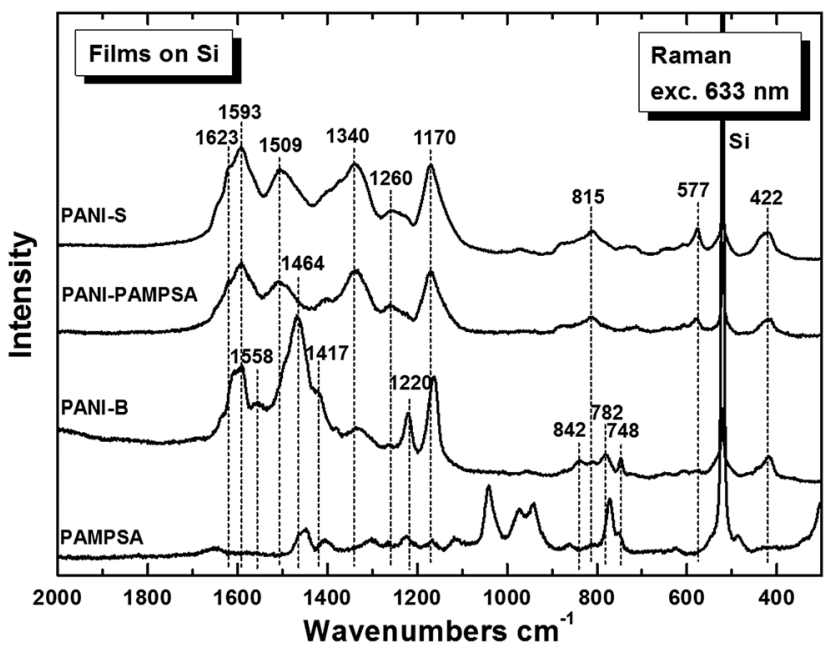

Fig. 2 Raman spectra of the in situ deposited PANI-S, PANI-B and PANI-PAMPSA on silicon window. Spectrum of pure PAMPSA is shown for comparison.

\subsection{Stem cell differentiation}

Stem cell differentiation in terms of cardiomyogenesis and neurogenesis was studied to reveal the ability of polyaniline to act as a biomaterial for stem cell technologies.

2.6.1. Cardiomyogenesis. ESC R1 line ${ }^{23}$ was propagated in an undifferentiated state by culturing on gelatinized tissue culture dishes in complete DMEM media. Cardiomyogeneses of ESC were then realized by elimination of leukemia inhibitory factor from cultivation media and by the formation of EBs using the hanging drop technique. Five-day-old EBs were transferred
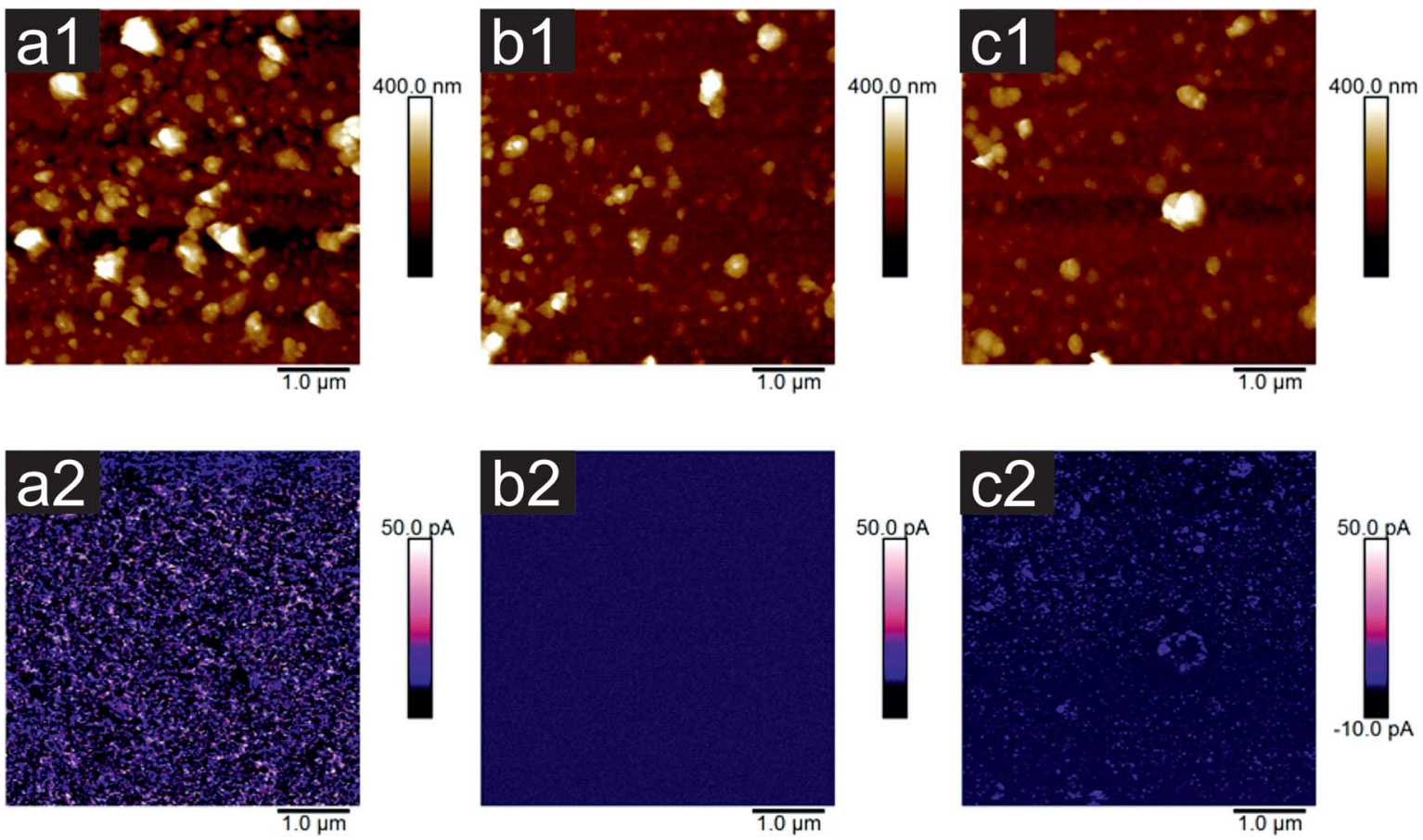

Fig. 1 AFM micrographs of roughness and conductivity of tested polyaniline surfaces. Roughness: (a1) PANI-S; (b1) PANI-B; (c1) PANI-PAMPSA. Peak current signal: (a2) PANI-S; (b2) PANI-B; (c2) PANI-PAMPSA. 

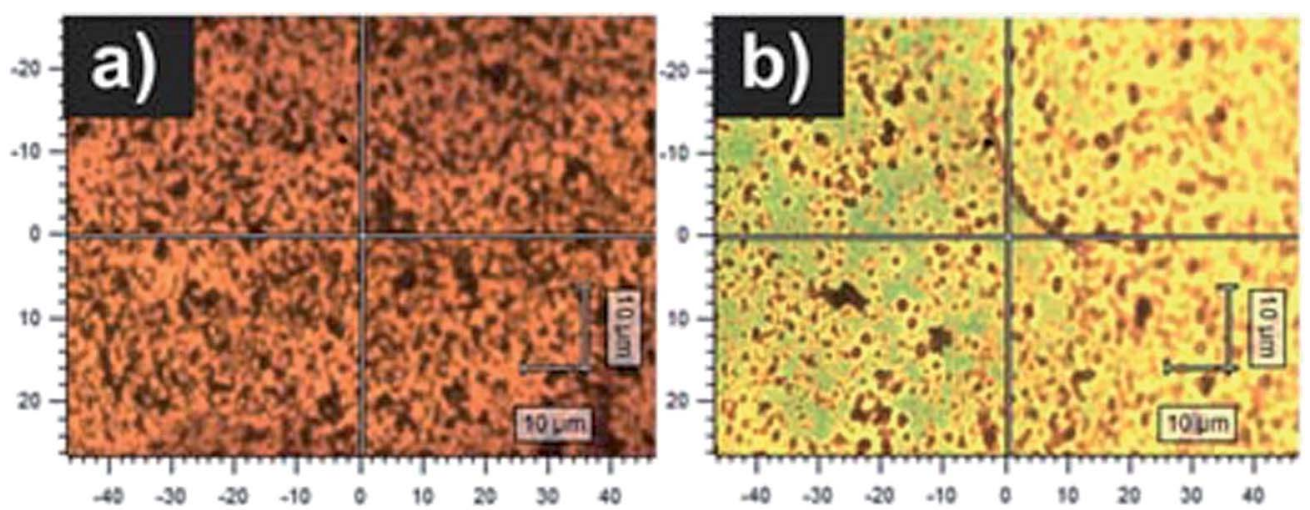

Fig. 3 Optical micrographs of the film of (a) PANI-B and (b) PANI-PAMPSA on silicon window.
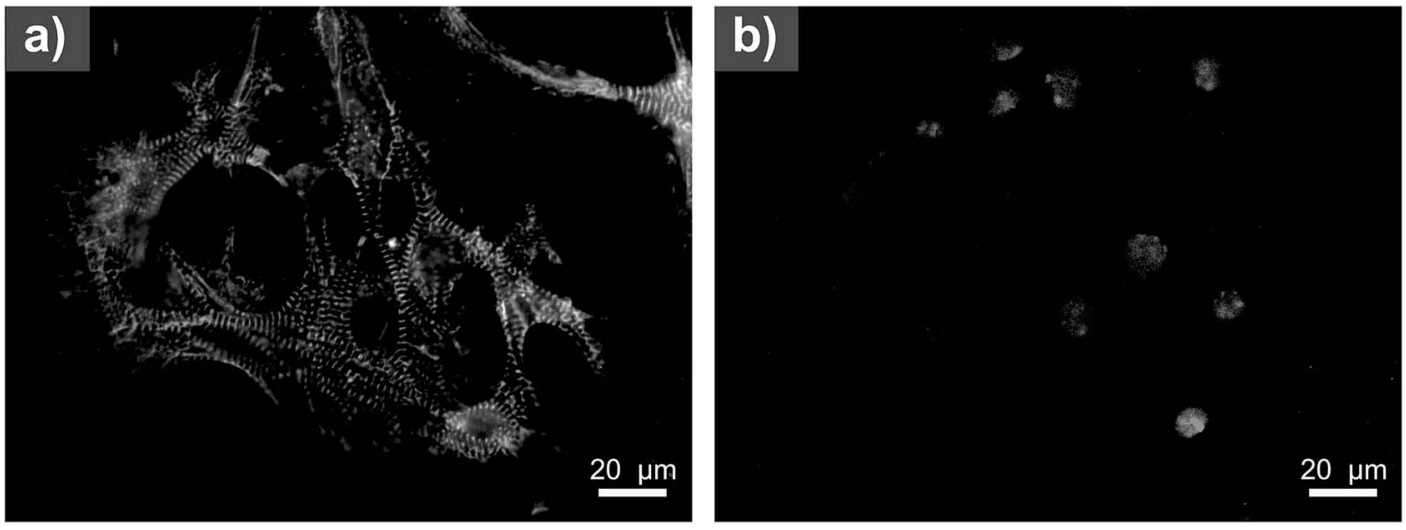

Fig. 4 Cardiomyocyte identity proved by the presence of myofibrils (a) using cardiomyocyte specific sarcomere alpha actinin antibody and counterstain by anti-mouse IgG antibody labelled by FITC; (b) the cell nucleus counterstain by DAPI.

to tissue culture dishes coated with gelatin $(0.1 \%$ aqueous solution, reference), PANI-S, PANI-B and PANI-PAMPSA, and cultivated either in complete DMEM media or serum-free ITS media. The detailed cultivation conditions are described by Vesela et al. ${ }^{25}$ and Kotasova et al. ${ }^{26}$ After 15 days, when clearly beating clusters within expanding EBs were recognized, cells were lysed for RNA isolation.

Total RNA was isolated by UltraClean RNA isolation kit (MO BIO, US). Complementary DNA was synthesized according to the manufacturer's instructions for M-MLV reverse transcriptase (Sigma-Aldrich, US). qRT-PCR was performed in a Roche
Light-Cycler using TaqMan PCR (Roche, Switzerland). The following program was used: initial activation step at $95{ }^{\circ} \mathrm{C}$ for $5 \mathrm{~min}$, followed by 40 cycles at $95{ }^{\circ} \mathrm{C}$ for $10 \mathrm{~s}$, annealing temperature (Table 1) for $10 \mathrm{~s}$, and $72{ }^{\circ} \mathrm{C}$ for $10 \mathrm{~s}$. The gene expression of each of the samples was expressed in terms of the threshold cycle normalized to the mean of the reference genes (Ribosomal protein L13 gene, Rpl13a) as described previously by Kotasova et al. ${ }^{26}$ Primers, probes, appropriate annealing temperatures, and PCR product lengths for the determined transcripts are listed in Table 1 . The myosin heavy chain $\alpha$ (Myh6), myosin heavy chain $\beta$ (Myh7), sarcomeric $\alpha$ aktinin

Table 1 Primer sequences for target and reference genes of cardiomyogenesis used in qRT-PCR assays

\begin{tabular}{|c|c|c|c|c|}
\hline \multicolumn{5}{|c|}{ Reference gene } \\
\hline Rpl13a & CATGAGGTCGGGTGGAAGTA, GCCTGTTTCCGTAACCTCAA & 116 & 60 & $\# 25$ \\
\hline \multicolumn{5}{|c|}{ Cardiomyocyte genes } \\
\hline Myh6 & CGCATCAAGGAGCTCACC, CCTGCAGCCGCATTAAGT & 61 & 60 & \# 6 \\
\hline Myh7 & CGCATCAAGGAGCTCACC, CTGCAGCCGCAGTAGGTT & 60 & 60 & \# 6 \\
\hline
\end{tabular}


Table 2 Primer sequences for target and reference genes of neurogenesis used in qRT-PCR assays

\begin{tabular}{|c|c|c|c|}
\hline Gene & Sequence & Product size (bp) & Annealing $\left({ }^{\circ} \mathrm{C}\right)$ \\
\hline \multicolumn{4}{|c|}{ Reference genes } \\
\hline$\beta$ Actin & GATCAAGATCATTGCTCCTCCT, TAAAACGCAGCTCAGTAACAG & 177 & 61 \\
\hline \multicolumn{4}{|c|}{ Neural genes } \\
\hline Sox 2 & GCGCCCTGCAGTACAACTCC, TTCGCAGTCCAGCCCTCACA & 362 & 66 \\
\hline GSX2 & TGGGAGGCTCCGATACCAG, TGTCGCGATTCTGATTCTCC & 140 & 60 \\
\hline Mash1 & GGTCTCGTCCTACTCCTCCG, GCTGCCATCCTGCTTCCAAA & 137 & 61 \\
\hline GFAP & GGAGGCACTTGCTCGGCTGG, TGGTGCTTTTGCCCCCTCGG & 212 & 63.5 \\
\hline
\end{tabular}

(Actn 2), and NK2 homeobox 5 (Nkx2.5) genes were chosen to detect the cardiomyogenesis.

2.6.2. Neurogenesis in neurospheres. Brain of a $13.5 \mathrm{dpc}$ mouse embryo was prepared and re-suspended in neurogenic, self-renewing media containing DMEM F12 $1: 1,1 \times \mathrm{N} 2$ and B27 supplements, $100 \mathrm{U} \mathrm{mL}^{-1}$ penicillin, $0.1 \mathrm{mg} \mathrm{mL}^{-1}$ streptomycin (Gibco-Invitrogen; US), $5 \mathrm{ng} \mathrm{mL}^{-1}$ of FGF-2 and $20 \mathrm{ng}$ $\mathrm{mL}^{-1}$ of EGF (PeproTech; US). ${ }^{27}$ Four-day-old neurospheres were seeded into tissue culture dishes coated with gelatin, PANI-S, PANI-B or PANI-PAMPSA, and cultivated in ITS media containing $3 \%$ fetal calf serum.

After further four days, cells were lysed for gene expression analyses. Gene expression was determined using qRT-PCR. Total RNA was isolated by MO BIO UltraClean RNA isolation kit (US). Complementary DNA was synthesized according to the manufacturer's instructions for M-MLV reverse transcriptase (Sigma-Aldrich; US). qRT-PCR was performed in a Roche LightCycler using the SYBRE Green method (Roche, Switzerland). The following program was employed: initial activation step at $95^{\circ} \mathrm{C}$ for $5 \mathrm{~min}$, followed by 40 cycles at $95^{\circ} \mathrm{C}$ for $10 \mathrm{~s}$, annealing temperature (Table 2) for $10 \mathrm{~s}$, and $72{ }^{\circ} \mathrm{C}$ for $10 \mathrm{~s}$. The gene expression of each sample was expressed in terms of the threshold cycle normalized to the mean of the reference genes as described previously. ${ }^{26}$ Primers, probes, appropriate annealing temperature, and product lengths for the determined transcripts are listed in Table 2. Beta actin and TATA-binding protein (TBP) were selected as the reference genes. Neurosphere adhesion was also determined by assessment of microphotographs taken 4 days after seeding, before collection to mRNA isolation for qRT-PCR.

\section{Results and discussion}

The composites and copolymers of polyaniline with biocompatible materials have previously been studied and their properties reported. Biological properties of pristine polyaniline films (PANI-S and PANI-B) have, however, been almost ignored despite their simple preparation procedure and possibility of being easily deposited on almost any material. The present study, therefore, focused on this topic. In addition, the impact of surface modification of polyaniline by biologically active polymeric acid PAMPSA is introduced. The behavior of stem cells on pristine and PAMPSA modified polyaniline surfaces is discussed with respect to their material properties.

\subsection{Surface energy}

The results from surface energy measurements obtained for PANI-S and PANI-B indicate almost the same values of the total surface energy $\left(\gamma^{\text {tot }}\right)$ as well as of its components representing both the disperse $\left(\gamma^{\mathrm{LW}}\right)$ and polar $\left(\gamma^{\mathrm{AB}}\right)$ parts (Table 3). A significant decrease was observed for $\gamma^{\text {tot }}$ on PANI-PAMPSA. In numerical values, the total surface energy decreased from $\gamma^{\text {tot }}=$ $53 \mathrm{mN} \mathrm{m}^{-1}$ (PANI-S) to $40 \mathrm{mN} \mathrm{m}^{-1}$ (PANI-PAMPSA). This is a simple proof of the presence of PAMPSA on the polyaniline surface.

\subsection{Atomic force microscopy}

Feasibility of the cells to adhere and proliferate is commonly reported to depend on the surface roughness and topography. ${ }^{28,29}$ In the present study, the AFM measurements were performed to reveal two important material properties influencing cell/polyaniline interaction: roughness and electrical properties. Considering roughness in terms of the $R_{\text {a }}$ parameter (Fig. 1), the results show that only small, insignificant differences can be detected among PANI-B (25 nm) and PANIPAMPSA $(21 \mathrm{~nm})$. In contrast, PANI-S exhibited a significantly rougher surface $(45 \mathrm{~nm})$ compared to the previously mentioned samples and also the highest image surface area difference, which was $42 \%$. The image surface area differences of remaining samples, correspondingly to $R_{\mathrm{a}}$ values, were lower, that is $24 \%$ for PANI-B and 15\% for PANI-PAMPSA. Previously, Wang

Table 3 Total surface energy $\left(\gamma^{\text {tot }}\right)$ and its disperse $\left(\gamma^{\mathrm{LW}}\right)$ and polar $\left(\gamma^{\mathrm{AB}}\right)$ parts determined on tested polyaniline surfaces

Surface energy components $\left(\mathrm{mN} \mathrm{m}^{-1}\right)$

\begin{tabular}{llll}
\hline Sample & $\gamma^{\text {tot }}$ & $\gamma^{\mathrm{LW}}$ & $\gamma^{\mathrm{AB}}$ \\
\hline PANI-S & 52.54 & 46.05 & 6.49 \\
PANI-B & 50.88 & 46.54 & 4.35 \\
PANI-PAMPSA & 39.96 & 37.05 & 2.91
\end{tabular}


et al. ${ }^{11}$ hypothesized that the nano-scale morphology of polyaniline films might have an impact on cell adhesion; however the differences in cell adhesion determined in the current work do not corroborate their assumption. The surface roughness observed on PANI-S, PANI-B and PANI-PAMPSA films in this study was too uniform to have any significant impact on cell adhesion. Considering the uniformity of all polyaniline films in terms of their thickness (125 $\pm 9 \mathrm{~nm})$, which originates from their chemical structure, ${ }^{22}$ it can be assumed that surface topography is not a key factor controlling cell adhesion or proliferation on these surfaces. Surface chemistry can therefore be regarded as a more important factor in polyaniline/cell interactions.

In contrast to roughness, bigger differences between the samples were detected in terms of their electrical properties. The peak current signal at a bias voltage of $200 \mathrm{mV}$ showed that more than $90 \%$ of measured values were found to be higher than $1120 \pm 10$ for PANI-S, $0.38 \pm 0.01$ for PANI-B and $210 \pm 1$ for PANI-PAMPSA (in pA). Thus PANI-B possessed the lowest current signal and for the remaining samples the current signal further increased in the order PANI-PAMPSA and PANI-S. Although the AFM based electrical properties are not, in numerical values, possible to compare with the conductivity values measured on the corresponding materials by the van der Pauw method, they are in good agreement with respect to their classifying in terms of the most and less conducing samples.

\subsection{Raman spectra}

The Raman spectrum of PANI-PAMPSA is very close to the spectrum of PANI-S (Fig. 2). Its spectrum exhibits the typical bands of the emeraldine salt. ${ }^{30,31}$ The peak at $1589 \mathrm{~cm}^{-1}$ is connected with $\mathrm{C}=\mathrm{C}$ stretching vibrations in a quinonoid ring, the peak with maximum at about $1506 \mathrm{~cm}^{-1}$ is assigned to the $\mathrm{N}-\mathrm{H}$ deformation vibrations associated with the semiquinonoid structures, contribution of the $\mathrm{C}=\mathrm{N}$ stretching vibrations in quinonoid units at $1480 \mathrm{~cm}^{-1}$ is expected. The band at 1337 $\mathrm{cm}^{-1}$ belongs to the $\mathrm{C} \sim \mathrm{N}^{+}$vibrations of delocalized polaronic structures. Benzene-ring deformation vibrations at $1260 \mathrm{~cm}^{-1}$ and the band at $1171 \mathrm{~cm}^{-1}$ of the $\mathrm{C}-\mathrm{H}$ in-plane bending vibrations of the semi-quinonoid or benzenoid rings are well observed in the spectrum, of PANI-S. The band at $810 \mathrm{~cm}^{-1}$ is linked to benzene-ring deformations and the band at $578 \mathrm{~cm}^{-1}$ to the amine deformation vibrations (in-plane) of the emeraldine salt structure. Out-of-plane deformations of the ring are connected with the bands at $520 \mathrm{~cm}^{-1}$ and $423 \mathrm{~cm}^{-1}$. The first is overlapped by a strong band situated at about $519 \mathrm{~cm}^{-1}$ comes from silicon substrate.

The spectrum of PANI-B corresponds to the spectrum of a typical emeraldine base (Fig. 2)..$^{30,31}$ The intensity of the peak of the vibrations in a quinonoid ring vanished the band assigned to $\mathrm{C}=\mathrm{N}$ vibrations in the quinonoid units situated at $1470 \mathrm{~cm}^{-1}$ dominates the spectrum. The peak situated at $1417 \mathrm{~cm}^{-1}$ connected with cross-linked phenazine-like structures appears in the spectrum. The intensity of the band of $\mathrm{C} \sim \mathrm{N}^{+}$stretching vibrations observed at $1335 \mathrm{~cm}^{-1}$ and of the band at $1260 \mathrm{~cm}^{-1}$ decreased. The band of $\mathrm{C}-\mathrm{N}$ stretching vibrations observed at
$1220 \mathrm{~cm}^{-1}$ and the band at $1161 \mathrm{~cm}^{-1}$ of $\mathrm{C}-\mathrm{H}$ bending vibrations of quinonoid rings are present in the spectrum of the PANI-B. A broad structural band with local maxima at $838 \mathrm{~cm}^{-1}$, $780 \mathrm{~cm}^{-1}$, and $746 \mathrm{~cm}^{-1}$ reflects benzene-ring deformations of variously substituted aromatic rings. The peaks belonging to the spectrum of PAMPSA are not detected in the spectra of PANIS or PANI-B. The optical images of the films of PANI-B and PANIPAMPSA (Fig. 3) demonstrate that modification of the film of PANI-B with PAMPSA also leads to the changes of color from brown to yellow-greenish in case of sample PANI-PAMPSA, which support the protonation of the film.

\subsection{Cardiomyocytes adhesion}

The potential of cardiomyocytes prepared in vitro from ESC to colonize on PANI-S, PANI-B and PANI-PAMPSA surfaces was determined under different experimental conditions. Isolated cardiomyocytes represent clusters of beating cells consisting of approximately 5-20 cells per cluster. The results show that cardiomyocytes were not able to adhere when cultivated in ITS media (without FCS), either on native or gelatin-coated polyaniline surfaces. After changing the cell culture medium to complete DMEM (with FCS), the cells successfully adhered on both a gelatinized or native polyaniline surfaces and the first clusters were observed $24 \mathrm{~h}$ after seeding on the gelatin coated surface. The influence of the FCS presence in the growth medium on adhesion of cardiomyocytes was also reported by Curtis and Forrester ${ }^{32}$ who described their identical behavior. Micrographs (Fig. 5) of cardiomyocytes on the gelatin-coated surfaces illustrate successful adhesion of the cells on the reference, PANI-S, and PANI-B and its absence on PANIPAMPSA. It can be concluded that the ability of cells to adhere to polyaniline surfaces depended on the presence of fetal calf serum in the medium and surface coating by gelatin. In the case of the reference, the presence of fetal calf serum caused it to perform more favorably compared to gelatin coating.

For the first $48 \mathrm{~h}$ after seeding, cells adhered to all tested surfaces; however, only on the reference their morphology changed in the expected manner, while on the other surfaces cells remained spheroidal. In addition, the spreading of cardiomyocytes occurred on the reference, and cells were compactly adhered. Later on, such spreading was also observed on PANI-B (day 9 after seeding). Although during the two-week cultivation period many cardiomyocytes also adhered to PANI-S and PANIPAMPSA, no spreading of cells was observed on these surfaces. The adhesion and proliferation of H9c2 cardiac myoblasts on polyaniline films prepared from saturated solutions of polyaniline in $N$-methyl-2-pyrrolidone were studied by Bidez et al. ${ }^{10}$ Irrespective of the fact that the initial cell adhesion was somewhat reduced, it was reported that the overall rate of cell proliferation was similar to a control and, after six days, the cells on the polyaniline surface formed a uniform, homogenous monolayer. Although, it is difficult to generalize results from one cell type to another, the results of Bidez et al. ${ }^{10}$ support the findings of the present work regarding PANI-B sample. Polyaniline is a material whose biocompatibility can crucially depend on the used dopant 

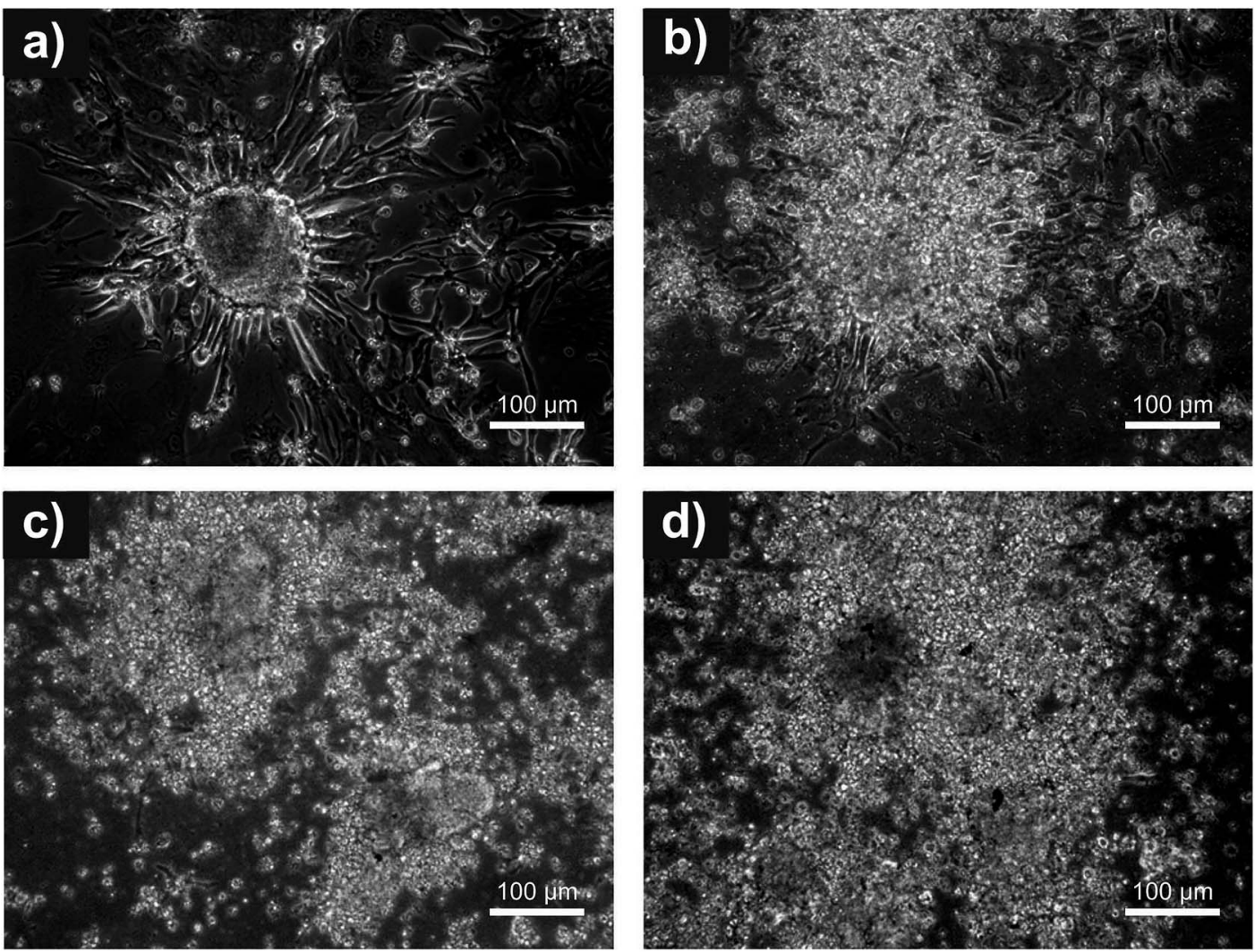

Fig. 5 Cardiomyocyte adhesion on polyaniline (selected from ESC clone HG8). Adhesion of cardiomyocyte on: (a) reference (tissue culture plastic coated with gelatin); (b) PANI-B; (c) PANI-S and (d) PANI-PAMPSA after 14 days cultivation on surfaces coated by gelatin in presence of DMEM containing fetal calf serum.

acids, as they can influence the leaching of toxic substances, and the surface characteristics of the sample. Investigation of this factor was conducted by Wang et al. ${ }^{11}$ In their work, polyaniline films were prepared by polymerizing deposition in situ with four different acids followed by casting onto the surface of a polytetrafluoroethylene substrate. Perchloric, hydrochloric, malic, and citric acids were studied. These polyaniline films were tested for adhesion and proliferation with PC-12 pheochromocytoma cells and it was found out that all films enabled cell adhesion and proliferation. Simultaneously, it was concluded that the effect of dopant acid on cell proliferation is negligible. Certain studies also revealed that cell adhesion was positively influenced by coating the different carrier materials with polyaniline. For example, Si wafer surfaces deposited with polyaniline were studied by Liu et al. ${ }^{12}$ using PC-12 cells derived from pheochromocytoma of the rat adrenal medulla. Although the testing proceeded for only four days, it was obvious that the polyanilinecoated surface allowed better cell adhesion and proliferation compared to bare Si surfaces. In the light of the above mentioned works and the results of this study, it is clear that polyaniline films can be useful as substrates for tissue engineering. These findings are consistent with ESC adhesion on materials combining polyaniline with various biocompatible polymers, e.g. human mesenchymal stem cells on chitin/polyaniline nanofibers, ${ }^{33}$ bone marrow mesenchymal stem cells on polyaniline containing hydrogel, ${ }^{34}$ or nerve stem cells on poly-L-lactide/ polyaniline nanofibers. $^{35}$

\subsection{Stem cell differentiation}

The conducting polymers are mostly considered for applications in the bio-engineering of electro-sensitive tissues., ${ }^{2,5}$ Therefore the investigation of complex nature of polyaniline behavior with respect to neurogenesis and cardiomyogenesis of ESC is of enormous interest.

3.5.1. Cardiomyogenesis in ESC. To analyze the possible effect of tested polyaniline films on cell development processes, a protocol enabling the differentiation of cardiomyocytes from ESC was employed. ${ }^{25,36}$ Primary evidence of the presence of cardiomyocytes is the observation of beating cells in culture. Under the studied conditions, beating foci were observed on surfaces from day 11 of differentiation (data not shown). qRTPCR analyses of the expressions of gene transcripts typical for cardiomyocytes (transcription factor Nkx2.5 and components of contractile apparatus, such as sarcomeric $\alpha$ actinin (ACTN2) and myosine heavy chains $\alpha$ Myh6) and $\beta$ (Myh7), did not show any significant difference between the reference and tested polyaniline surfaces (Fig. 6). Thus, it can be concluded that under the tested conditions cardiomyogenesis in ESC proceeds in the same manner on all surfaces. In the present study, where no external electrical field was applied, the beating 

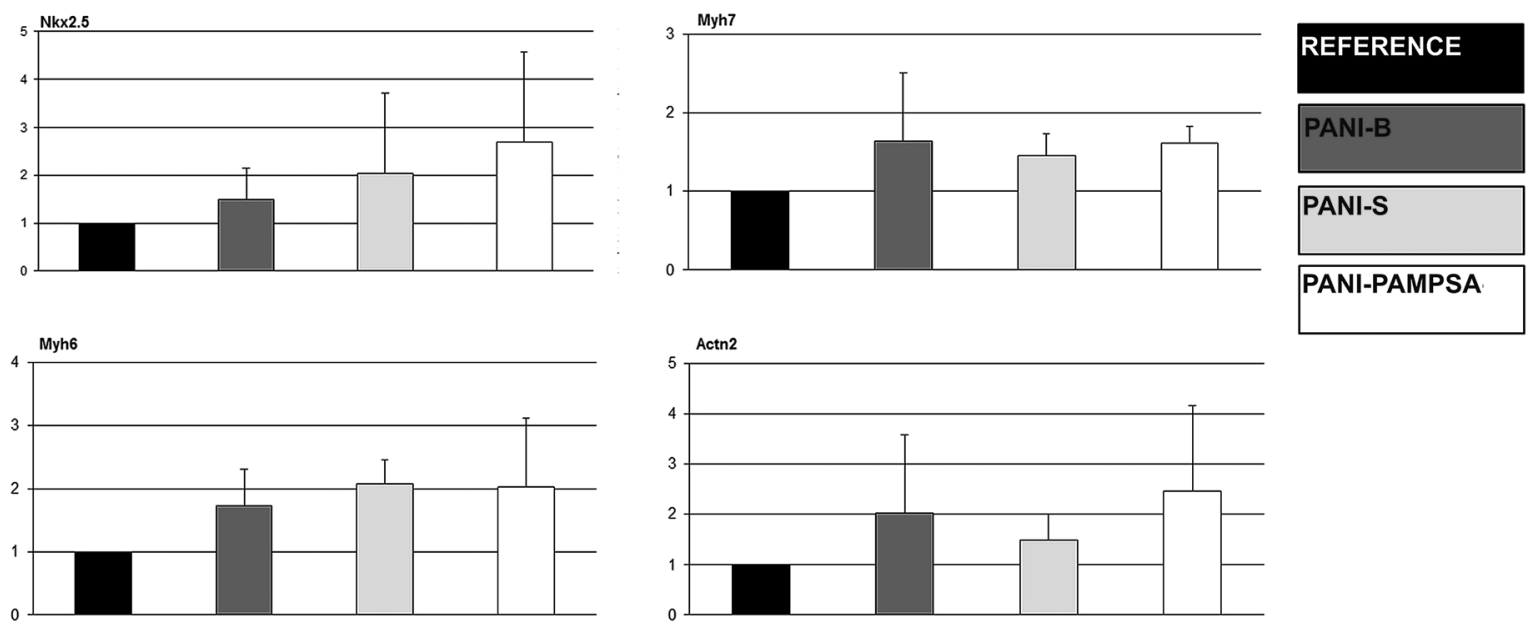

Fig. 6 Relative mRNA expression of cardiomyocytes markers gene.

of cardiomyocytes observed on the tested conducting films was comparable to that on the reference. The synchronization of the beating of cardiomyocyte clusters induced by electrical impulses, as described by Hsiao et al., ${ }^{5}$ can therefore be expected. Developmental processes are very sensitive to environment effects. ${ }^{37}$ Cardiomyogenesis in ESC is, for example, standardized method for the testing of embryo toxicity, ${ }^{38}$ thus, it can be also concluded that the tested surfaces possess no toxic or embryotoxic effect.

3.5.2. Neurogenesis in neurospheres. The biocompatibility of polyaniline surfaces was also tested with respect to neural progenitors. Neural progenitors were isolated from mouse brain of $13.5 \mathrm{dpc}$ and expanded in self-renewing media in the presence of growth factors inhibiting their differentiation.
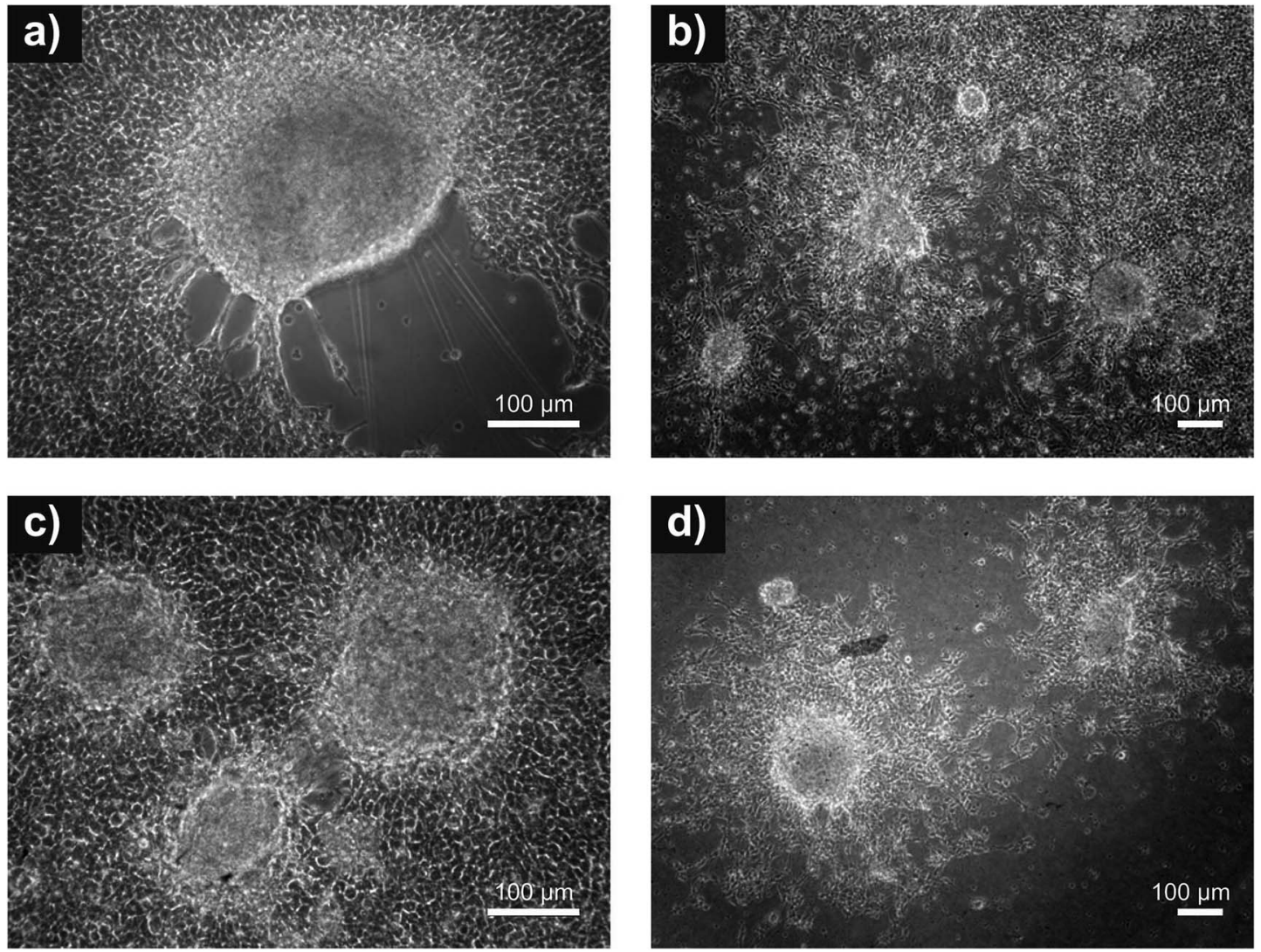

Fig. 7 Neuro adhesion. Adhesion of neurospheres on: (a) reference (tissue culture plastic); (b) PANI-B; (c) PANI-S and (d) PANI-PAMPSA. Absence of cell debris indicating cytotoxicity is not observed. 

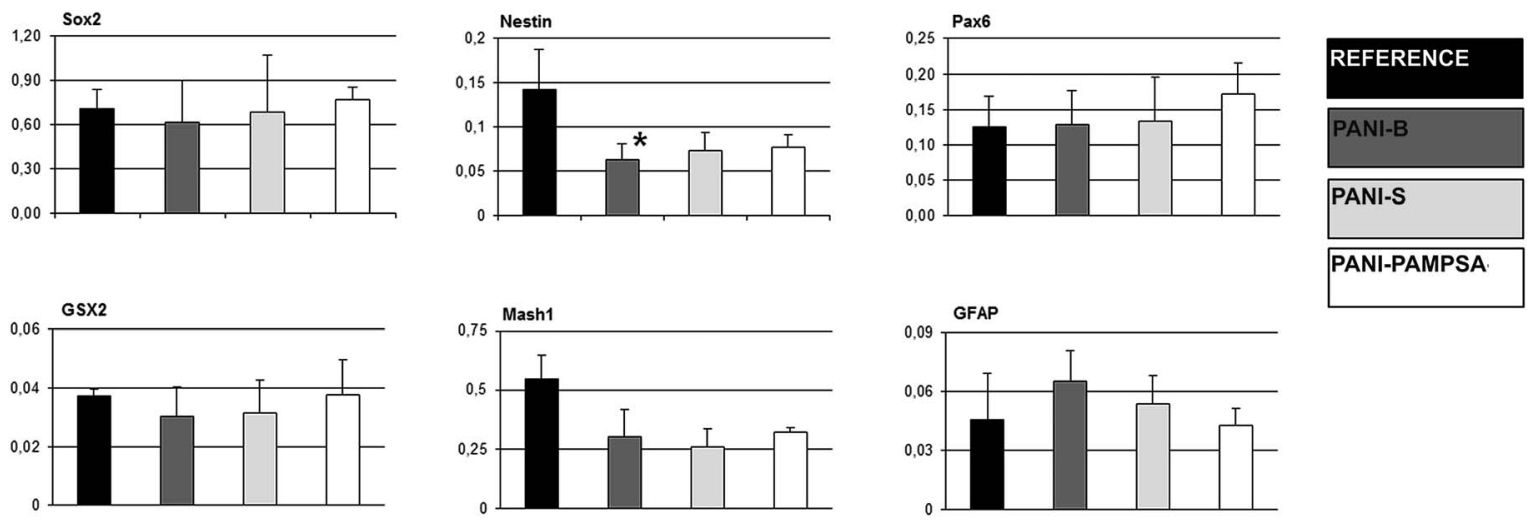

Fig. 8 Relative mRNA expression of neurospheres markers gene.

Expanding neural progenitors forming neurospheres were seeded onto the polyaniline and reference surfaces in differentiating media depleted to self-renewing growth factors. As can be seen in Fig. 7, neurospheres adhered to, and spread well on the reference and PANI-B surfaces, less well on the PANI-S surface, and only in a limited way on the PANI-PAMPSA surface. After the next 4 days of culture, cells were collected and the expression of the neural specific transcripts was determined. No significant differences in these expressions were observed. Similarly to results recorded with cardiomyogenesis, it can be concluded that PANI-S and PANI-B have no significant effect on the development of neuronal progenitors. In the case of the PANI-PAMPSA, the cells did not conform to their standard behavior; however, differentiation seemed to be unaffected (Fig. 8).

Generally, the stem cell growth on the tested surfaces corresponded to cell adhesion, and it can be concluded that, in terms of cell compatibility, pristine polyaniline (PANI-S and PANI-B) possesses more favorable properties compared to PANIPAMPSA. The cardiomyogenesis and neurogenesis on all tested surfaces were not different from those observed on the reference. The absence of a negative impact of polyaniline on ESC differentiation, which was originally confirmed in our study, suggests that this polymer, even in pristine form, can be safely used in advanced biomedical applications. As ESC interaction with polyaniline has not previously been studied in terms of cardiomyogenesis and neurogenesis, these outcomes can be considered as novel and original.

\section{Conclusions}

The original study presented here explores the behavior of embryonic stem cells on the surfaces of pristine and modified polyaniline films. The results revealed that cell behaviour on pristine polyaniline, mainly polyaniline base, is comparable to that observed on reference tissue culture plastic. The modification of pristine polyanilines with PAMPSA decreases embryonic stem cell adhesion and disabled spreading on this surface. In addition, embryonic stem cell differentiation on polyaniline surfaces is presented for the first time. It was revealed that pristine polyaniline has no negative influence on cardiomyogenesis or neurogenesis and is free of embryotoxicity, which opens up the possibility of devising a wide range of potential applications for this conducting polymer in the field of biomedical engineering.

\section{Author contributions}

Petr Humpolíček and Katarzyna Anna Radaszkiewicz contributed equally to the manuscript. The manuscript was written through contributions of all authors. Sample preparation was carried out by VK and JS. MT performed Raman Spectroscopy, ML and AM performed AFM and Surface Energy evaluation. The cell studies was carried out by PH, JP, KAR, HV and ZK. All authors have given approval to the final version of the manuscript.

\section{Acknowledgements}

The financial support of the Czech Science Foundation (1308944 S) is gratefully acknowledged. This work was supported by the Ministry of Education, Youth and Sports of the Czech Republic - Program NPU I (LO1504).

\section{References}

1 T. H. Qazi, R. Rai and A. R. Boccaccini, Biomaterials, 2014, 35, 9068-9086, DOI: 10.1016/j.biomaterials.2014.07.020.

2 P. H. Peckham and J. S. Knutson, Annu. Rev. Biomed. Eng., 2005, 7, 327-360, DOI: 10.1146/annurev.bioeng.6.040803.140103.

3 L. C. Kloth, The International Journal of Lower Extremity Wounds, 2005, 4, 23-44, DOI: 10.1177/1534734605275733.

4 D. M. Ciombor and R. K. Aaron, Foot Ankle Clin., 2005, 10, 579-593, DOI: S1083-7515(05)00077-X.

5 C. W. Hsiao, M. Y. Bai, Y. Chang, M. F. Chung, T. Y. Lee, C. T. Wu, B. Maiti, Z. X. Liao, R. K. Li and H. W. Sung, Biomaterials, 2013, 34, 1063-1072, DOI: 10.1016/ j.biomaterials.2012.10.065.

6 J. A. Genovese, C. Spadaccio, J. Langer, J. Habe, J. Jackson and A. N. Patel, Biochem. Biophys. Res. Commun., 2008, 370, 450-455, DOI: 10.1016/j.bbrc.2008.03.115. 
7 J. F. Feng, J. Liu, X. Z. Zhang, L. Zhang, J. Y. Jiang, J. Nolta and M. Zhao, Stem Cell, 2012, 30, 349-355, DOI: 10.1002/ stem.779.

8 I. Jun, S. Jeong and H. Shin, Biomaterials, 2009, 30, 20382047, DOI: 10.1016/j.biomaterials.2008.12.063.

9 N. A. Rahman, V. Feisst, M. E. Dickinson, J. Malmstroem, P. R. Dunbar and J. Travas-Sejdic, Mater. Chem. Phys., 2013, 138, 333-341, DOI: 10.1016/j.matchemphys.2012.11.065.

10 P. R. Bidez, S. X. Li, A. G. MacDiarmid, E. C. Venancio, Y. Wei and P. I. Lelkes, J. Biomater. Sci., Polym. Ed., 2006, 17, 199212, DOI: $10.1163 / 156856206774879180$.

11 H. J. Wang, L. W. Ji, D. F. Li and J. Y. Wang, J. Phys. Chem. B, 2008, 112, 2671-2677, DOI: 10.1021/jp0750957.

12 S. Liu, J. Wang, D. Zhang, P. Zhang, J. Ou, B. Liu and S. Yang, Appl. Surf. Sci., 2010, 256, 3427-3431, DOI: 10.1016/ j.apsusc.2009.12.046.

13 C. L. Bayer, I. J. Trenchard and N. A. Peppas, J. Biomater. Sci., Polym. Ed., 2010, 21, 623-634, DOI: 10.1163/ $156856209 \times 434647$.

14 H. Peng, X. Liu, R. Wang, F. Jia, L. Dong and Q. Wang, J. Mater. Chem. B, 2014, 2, 6435-6461, DOI: 10.1039/ c4tb00344f.

15 D. Paneva, O. Stoilova, N. Manolova, D. Danchev, Z. Lazarov and I. Rashkov, e-Polym., 2003, 052.

16 E. Yancheva, D. Paneva, D. Danchev, L. Mespouille, P. Dubois, N. Manolova and I. Rashkov, Macromol. Biosci., 2007, 7, 940-954, DOI: 10.1002/mabi.200700056.

17 H. Setoyama, Y. Murakami, K. Inoue, H. Iwata, H. Kitamura, T. Shimada, H. Kaji, Y. Ikada and M. Imamura, Transplant. Proc., 1999, 31, 2818-2822, DOI: S0041-1345(99)00579-5.

18 P. Humpolíček, Z. Kuceková, V. Kašpárková, J. Pelková, M. Modic, I. Junkar, M. Trchová, P. Bober, J. Stejskal and M. Lehocký, Colloids Surf., B, 2015, 133, 278-285.

19 O. L. Gribkova, A. A. Nekrasov, V. F. Ivanov, O. A. Kozarenko, O. Y. Posudievsky, A. V. Vannikov, V. G. Koshechko and V. D. Pokhodenko, Synth. Met., 2013, 180, 64-72, DOI: 10.1016/j.synthmet.2013.08.004.

20 J. Stejskal and R. G. Gilbert, Pure Appl. Chem., 2002, 74, 857867, DOI: $10.1351 /$ pac200274050857.

21 P. Bober, P. Humpolicek, J. Pachernik, J. Stejskal and T. Lindfors, $R S C A d v$. , 2015, 5, 50328-50335.

22 J. Stejskal and I. Sapurina, Pure Appl. Chem., 2005, 77, 815826, DOI: $10.1351 /$ pac200577050815.
23 A. Nagy, J. Rossant, R. Nagy, W. Abramow-Newerly and J. C. Roder, Proc. Natl. Acad. Sci. U. S. A., 1993, 90, 8424-8428. 24 M. G. Klug, M. H. Soonpaa, G. Y. Koh and L. J. Field, J. Clin. Invest., 1996, 98, 216-224, DOI: 10.1172/JCI118769.

25 I. Vesela, H. Kotasova, S. Jankovska, J. Prochazkova and J. Pachernik, Folia Biol., 2010, 56, 165-172, DOI: FB2010A0023.

26 H. Kotasova, I. Vesela, J. Kucera, Z. Houdek, J. Prochazkova, M. Kralickova and J. Pachernik, J. Cell. Biochem., 2012, 113, 563-570, DOI: $10.1002 /$ jcb.23380.

27 J. Mokry and J. Karbanova, Folia Biol., 2006, 52, 149-155, DOI: FB2006A0018.

28 D. C. Miller, A. Thapa, K. M. Haberstroh and T. J. Webster, Biomaterials, 2004, 25, 53-61, DOI: 10.1016/S0142-9612(03) 00471-X.

29 C. H. Wang, Y. Q. Dong, K. Sengothi, K. L. Tan and E. T. Kang, Synth. Met., 1999, 102, 1313-1314, DOI: 10.1016/S0379-6779(98)01006-6.

30 Z. Rozlivkova, M. Trchova, I. Sedenkova, M. Spirkova and J. Stejskal, Thin Solid Films, 2011, 519, 5933-5941, DOI: 10.1016/j.tsf.2011.03.025.

31 M. Trchova, Z. Moravkova, I. Sedenkova and J. Stejskal, Chem. Pap., 2012, 66, 415-445, DOI: 10.2478/s11696-0120142-6.

32 A. S. Curtis and J. V. Forrester, J. Cell Sci., 1984, 71, 17-35. 33 B. K. Gu, M. S. Kim, C. M. Kang, J. Kim, S. J. Park and C. Kim, J. Nanosci. Nanotechnol., 2014, 14, 7621-7626, DOI: 10.1166/ jnn.2014.9575.

34 L. Li, J. Ge, B. Guo and P. X. Ma, Polym. Chem., 2014, 5, 28802890, DOI: 10.1039/c3py01634j.

35 M. P. Prabhakaran, L. Ghasemi-Mobarakeh, G. Jin and S. Ramakrishna, J. Biosci. Bioeng., 2011, 112, 501-507, DOI: 10.1016/j.jbiosc.2011.07.010.

36 J. Prochazkova, M. Kabatkova, L. Smerdova, J. Pachernik, D. Sykorova, J. Kohoutek, P. Simeckova, E. Hruba, A. Kozubik, M. Machala and J. Vondracek, Toxicol. Sci., 2013, 134, 258-270, DOI: 10.1093/toxsci/kft110.

37 J. Rohwedel, K. Guan, C. Hegert and A. M. Wobus, Toxicol. In Vitro, 2001, 15, 741-753, DOI: S0887-2333(01)00074-1.

38 M. Balls and E. Hellsten, ATLA, Altern. Lab. Anim., 2002, 30, 265-268. 